\title{
General Creep-Fatigue Life Prediction Models
}

\author{
James Toland', and Tarun Goswami ${ }^{2}$ \\ 1. New Product Development, Virco Manufacturing, PO Box 5000, Conway' AR 72033. \\ ${ }^{2}$ Department of Mechanical Engineering, The T.I. Smull College of Engineering. \\ Ohio Northern University, 'Ada, OH 45810 USA
}

\begin{abstract}
This paper presents a data bank that was compiled from published and unpublished sources. Using these data, low cycle fatigue curves were generated under a range of test conditions showing the effect of test parameters on the Coffin-Manson behavior of steel alloys. Generic equations have been developed in this paper to predict the creep-fatigue life of high temperature materials. Several new multivariate equations were developed to predict the creep-fatigue life of following alloy groups; 1) $\mathrm{Cr}$-Mo steels, 2) stainless steels and 3) generic materials involving the materials from the following alloy groups, solder, copper, steels, titanium, tantalum, and nickel based alloys. Statistical analyses were performed in terms of coefficient of correlation $\left(\mathrm{R}^{2}\right)$ and normal distribution plots and recommended these methods in the design of components operating at high temperatures.
\end{abstract}

Keywords: Creep-Fatigue, Life Prediction, Fatigue Life, High Temperature Materials

\section{INTRODUCTION}

The operating conditions of many engineering components from power plant equipment, gas turbine engines, rocket motors and other applications are known to be complex. The service loads in such applications change with time in order to meet with a specific demand. Therefore, assuring plant safety requires that conservative methodology be developed and used in the design of critical components operating at high stress and temperatures. Even though considerable efforts have been made to generate creep-fatigue data for various steel alloys, yet not all the material characteristics are fully understood. Start-up and shutdown cycles impose fatigue damage at localized areas, where material is inhomogeneous or discontinuous, and areas where stress is concentrated as a result of geometrical constraints. A major part of application requires that a component be held at near steady conditions, such as during the period between the shutdowns of a gas turbine engine or power plant turbine. The time during which loads are held near steady conditions is known as a dwell time. During a dwell time, under high temperature applications, creep deformation takes place, if favorable stress and temperature combinations are maintained. Therefore, failure mechanisms under such loading conditions are a result of complex interactions of creep and fatigue processes within low cycle fatigue regime. For rocket motors the life is in terms of one cycle only, whereas for other 
components, for example, gas turbine blades and discs, life may range in several thousand hours. Therefore, creep-fatigue life prediction issues are very important in design in order to understand the failure mechanisms and life assessment of a component.

The operating conditions of power equipment range from a) strain control, simulating thermally induced stresses, to b) load controlled, simulating constant centrifugal stresses. In the former, thermally induced stress decays with time owing to stress relaxation, whereas in the latter, constant centrifugal stress causes a steady state loading. The difference between these two frameworks is in terms of remaining life, after formation of a detectable crack, which is much greater in the case of strain control tests. For the load control framework, the high cycle fatigue, and mixed fatigue phases are studied. In this regime, the life prediction is based on the assumption that a crack like discontinuity is present in a component and modeling its growth till it becomes critical. Numerous empirical life prediction models $/ 1-13 /$ exist in the literature showing fatigue resistance a function of test and/or material parameters. While test parameters such as dwell time, and temperature show interactions of creep and fatigue, complex interactions with environmental processes are very difficult to incorporate in a life prediction model. The present paper describes the results of extensive effort to compile the low cycle fatigue (LCF) data of steel alloys, analytically describes the observed variation of cyclic life as a function of the principal test variables and comments on the applicability of methods in life prediction $/ 1-3 /$. A summary of materials selected for this study is presented below:

Solder alloys: used in the electronics industry for interconnection purposes, exposed to low cycle and thermal fatigue conditions

Copper alloys: used as nozzle liner materials in space shuttle main engine, subjected to creep-fatigue conditions

Steel alloys: used in the construction of pipelines, support structures, turbine rotors components in power, chemical, and other industries, fail by creep-fatigue mode

Titanium alloys: used in a range of applications, this paper considers only aerospace usage failure modes are low and high cycle fatigue

Tantalum alloys: used in high temperature applications and failure modes are same as above

Superalloys: used in the gas turbine engine, such as disks and blades, fail by low cycle fatigue, creep and other modes.

\section{LOW CYCLE FATIGUE DATA}

This section presents the LCF data in terms of plastic strain range and cycles to failure on a log-log scale. The data presented shows LCF life a function of test parameters employed (Coffin-Manson plots). Parameters varied were temperature, strain rates, dwell time, and environment, simulating a particular environment in which these materials are used. Therefore, numerous empirical relations can be developed from these data sets and used in interpreting LCF behavior of steel alloys. Figure 1 presents LCF behavior of $\mathrm{ICr}-\mathrm{Mo}-\mathrm{V}$ tested under numerous conditions. Figures 2 and 3 show the same data for $2.25 \mathrm{Cr}-\mathrm{I} \mathrm{Mo}$ and $9 \mathrm{Cr}$ 1 Mo steels, respectively. These are typical plots generated to show the volume of data compiled and their test conditions. Due to lack of space, all the data on different materials are not presented here. 




Fig. 1: Low cycle fatigue behavior of $1 \mathrm{Cr}-\mathrm{Mo}-\mathrm{V}$ steel.



Fig. 2: Low cycle fatigue behavior of $2.25 \mathrm{Cr}$-Mo steels. 


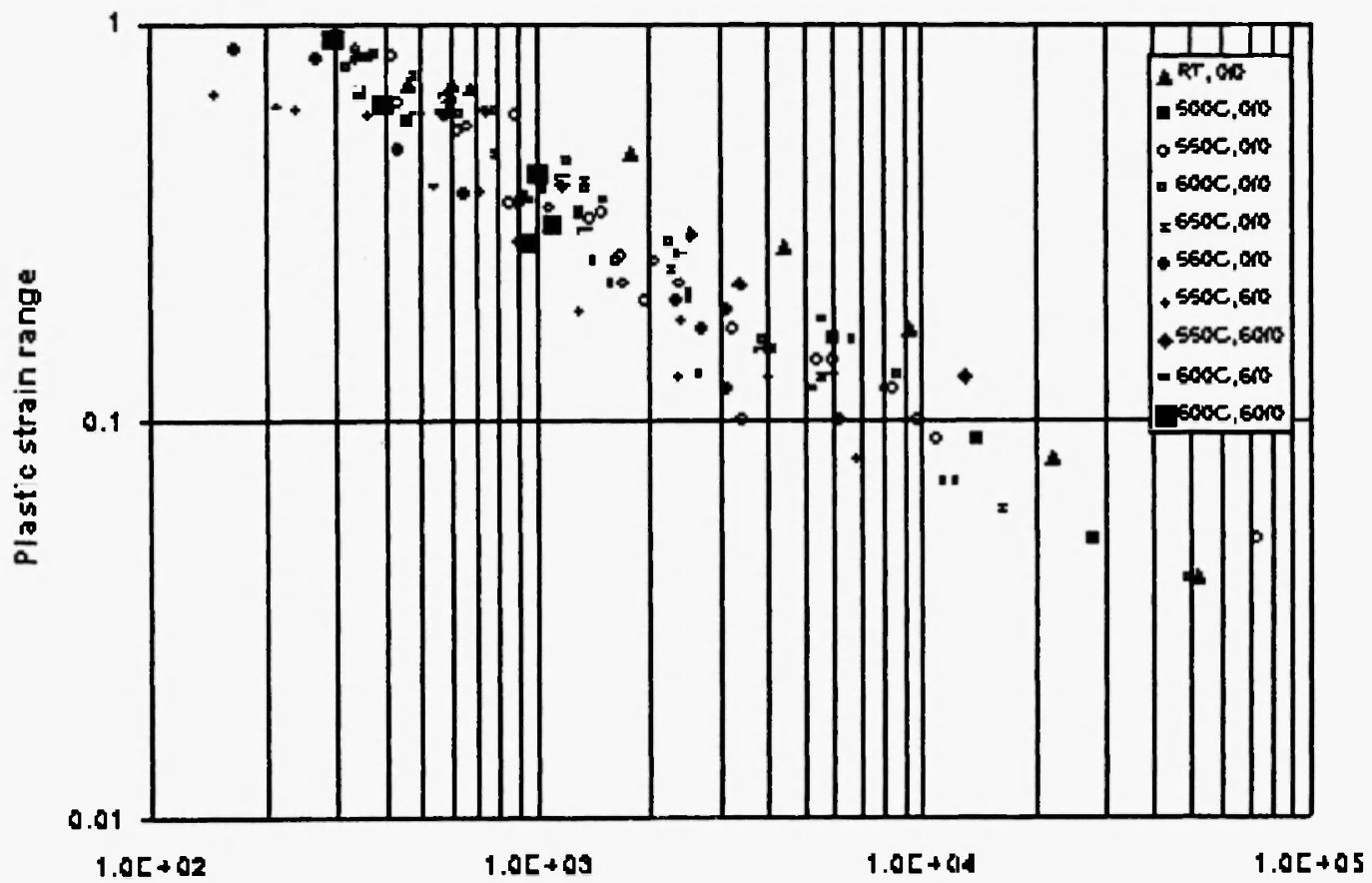

Fig. 3: Low cycle fatigue behavior of $9 \mathrm{Cr}-1 \mathrm{Mo}$ steels.

\section{GENERIC EQUATIONS}

Statistical multivariate equations are likely to be an alternate approach to creep-fatigue life prediction due mainly to different failure mechanisms accompany different test types and materials. Therefore, this paper presents this framework of creep-fatigue life prediction and shows a methodology to develop such multivariate best-fit equations that may be valuable in the design of engineering components. Multivariate equations were derived by a number of workers $/ 11-14 /$ to predict the fatigue behavior of stainless steels. These equations were originally derived to predict the low cycle fatigue response curves of SS 304 and recommended in design by American Society of Mechanical Engineers. Other similar extrapolation equations were developed for SS 304, 316, and 321/12-13/. Such developments were centered within the laboratories and organizations that managed testing efforts (such as ASME programs, NASA, DoE laboratories, and private companies) and controlled testing and therefore the data. Therefore, these equations were limited in the total number of terms used in the model and also the number of test data sets for each case. For this research effort a part of the original data was declassified by one of the DoE laboratories, and used to develop the generic equations. Therefore, the current form of the equations is more complete with a very high coefficient of correlation $\left(R^{2}\right)$ value.

An attempt was made to develop a methodology to derive new multivariate or generic equations. The following alloy groups were selected, and for each case one model was derived.

1. Cr-Mo steels

2. Stainless steels

3. Generic materials (includes Cr-Mo steels, stainless steels, solder alloys, copper alloys, titanium alloys, tantalum alloys, and superalloys 1782 data points) 
The data contained several variables in the testing, whereas effects of composition, microstructure, grain size, heat treatment and other material parameters were isolated and/or ignored to develop generic life prediction models. To simplify this effort, only four independent variables were utilized namely; strain range, strain rate, dwell time, and temperature. These independent variables were found to alter the cyclic life, which was a dependent variable of the four independent variables identified above. A number of software packages were used such as Microsoft Excel, Mat-Lab, Simstat and Statistical Analysis System (SAS) to identify the contributing terms and then to limit the number of terms of the generic equation. The transformation functions used were:

$$
\begin{aligned}
& \mathrm{S} \text { - a strain range parameter }\left(\mathrm{S}=\log \left(\Delta \varepsilon_{\mathrm{t}} / 100\right),\right. \\
& \mathrm{R} \text { - a strain rate parameter }(\mathrm{R}=\log \dot{\varepsilon}), \\
& \mathrm{T} \text { - a temperature parameter }(T=T / 100) \text {, and } \\
& \mathrm{H} \text { - a hold time parameter }\left\{H=\log \left(1+\mathrm{t}_{\mathrm{h}}\right)\right\},
\end{aligned}
$$

where $\Delta \varepsilon_{t}$ is the \% total strain range, $\dot{\varepsilon}$ the strain rate $(1 / \mathrm{sec}), T_{c}$ is test temperature $\left({ }^{\circ} \mathrm{C}\right), N_{f}=\sqrt{ }\left(\log \left(N_{f}\right)\right.$ and $t_{h}$ is the duration of hold time in hours, in the above equation.

The use of transformation functions reduced the scatter in the residual data, which was the difference between the predicted and observed cyclic life. Typical trends in the residual plots are one of the following; funnel trend, double bow trend, and residual non-linear trend, shown in Fig. 4. The experimental and predicted cycles to failure are presented in the plot showing various inconsistencies in this figure. Therefore,

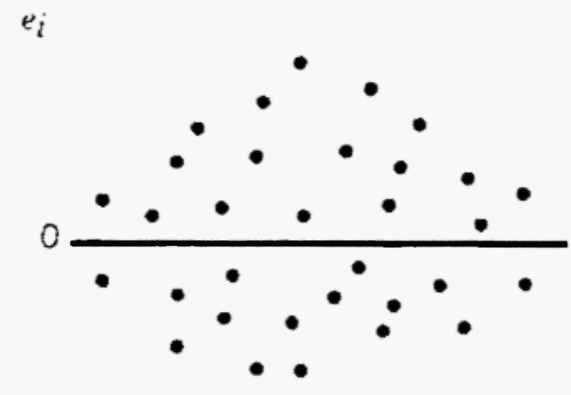

(a)



(b)

$e_{i}$

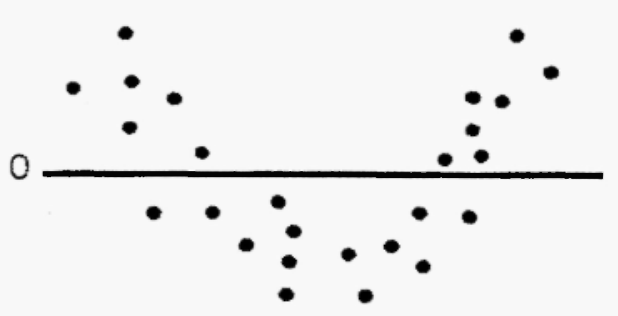

(c)

Fig. 4: Trends in the observed and predicted cycles to failure plot; (a) Double bow trend, (b) Funnel trend, and (c) Non-linear trend. 
it is desired that the data be scattered through the scale and not show the above trends, Fig. 4. The transformation functions used in the analysis helped eliminating above trends from forming. The trends for this analysis are presented in the following sections.

\subsection{Generic Model for Cr-Mo Steels}

A total of 479 data sets were used from the following low alloy steels: $0.5 \mathrm{Cr}-\mathrm{Mo}, 1 \mathrm{Cr}-\mathrm{Mo}-\mathrm{V}, 1.25 \mathrm{Cr}-$ $\mathrm{Mo}, 2.25 \mathrm{Cr}-\mathrm{Mo}, 2.25 \mathrm{Cr}-\mathrm{Mo}-\mathrm{V}$, and $9 \mathrm{Cr}-\mathrm{I}$ Mo to derive a multivariate equation. The dwell times ranged from a few seconds to 48 hours and temperature varied from room temperature to $600^{\circ} \mathrm{C}$. The total strain range varied from $0.1 \%$ to as high as $2.5 \%$ and strain rate, though not specified for each test. varied from $5 \times 10^{-3}$ to as low as $5 \times 10^{-5} / \mathrm{sec}$. The four independent variables identified were used in the Statistica! Analysis System and a best-fit equation was derived for $4^{\text {th }}$ power optimized for maximum $\mathrm{R}^{2}$ value. It is shown that higher power terms do not contribute to further improvement in the $R^{2}$ value from the plot, Figure 5. showing number of terms that show a plateau, meaning after certain number of terms further terms add only marginally to the $R^{2}$ improvement. The analysis of variance involved a corrected total degree of freedom 473 terms, sum of squares 13.50 , mean square of 0.14955 , $F$ value of 18.99. A 69 variable, multivariate equation was developed which gave a $\mathrm{R}^{2}$ value of $76.43 \%$. Thus, $23.57 \%$ of the total variations remain unexplained. This could be due to random test samples that were collected, test run out. premature failures, or to an additional variable, which has not been considered.

Figure 6 shows the residual scatter plot of the experimental and predicted lives under a range of test conditions and data compiled. It is warned that several tests either had run outs or, prematurely failed early on in their fatigue life. Therefore, those data points are clearly shown in the figure. A statistical analysis in terms of normal cumulative distribution and cumulative distribution of residuals are plotted in Fig. 7 . The

\section{Term Reduction}



Fig. 5: Number of terms versus coefficient of correlation $\left(\mathrm{R}^{2}\right)$ value for $\mathrm{Cr}$-Mo steels. 




Fig. 6: Scatter plot of experimental and predicted lives.

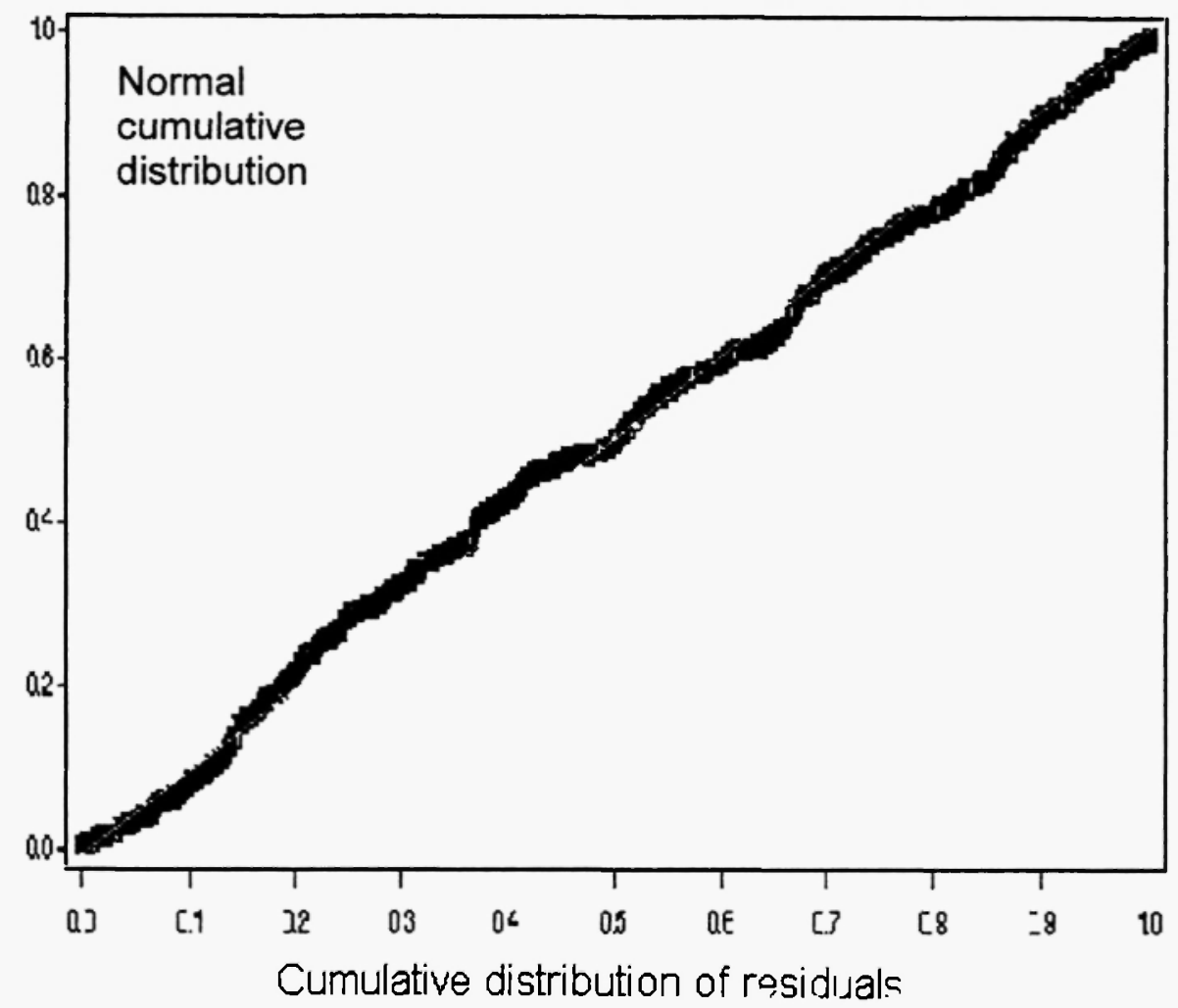

Fig. 7: Normal cumulative distribution with the cumulative distribution of residuals showing a straight line behavior (479 data sets). 
closer the trend corresponds to I to I line, the better the model is developed. The observed trend follows very closely the I to I line, and therefore offers high reliability (over $76 \%$ success).

The generic model for Cr-Mo steel alloys has the following form:

$N_{f}=-2081.00004-96.58004 S^{2}-157.18380 R^{2}-33.27409 T^{2}-34.18196 S^{3}-6.81706 R^{3}+5.12091 H^{3}+$ $0.99174 \mathrm{~T}^{3}-3.97033 \mathrm{~S}^{4}+0.09245 \mathrm{R}^{4}-4.36154 \mathrm{H}^{4}-0.00567 \mathrm{~T}^{4}+7.03397 \mathrm{~S}^{2} \mathrm{H}+91.06390 \mathrm{~S}^{2} \mathrm{~T}+76.69415$ $\mathrm{S}^{3} \mathrm{R}+24.38854 \mathrm{RH}+173.20087 \mathrm{RT}-1.41757 \mathrm{HT}-1.41757 \mathrm{R}^{2} \mathrm{~S}-1.90162 \mathrm{R}^{3} \mathrm{H}-0.23208 \mathrm{R}^{4} \mathrm{H}-3.91813$ $R^{3} T-0.21865 R^{4} T-1.48672 R^{3} S-0.08994 R^{4} S+6.89747 H^{2} T-4.13082 H^{3} T+3.79652 H^{4} T+11.04750$ $H^{2} R+1.19693 H^{4} R-14.18916 H^{2} S+8.76843 H^{3} S-0.04130 H^{4} S+4.71022 S^{2} R^{2}+1.94284 \mathrm{~S}^{3} R^{2}+0.18897$ $S^{4} R^{2}+0.09321 R^{3} S^{3}+0.00457 R^{4} S^{3}+5.29123 R^{2} H^{2}+1.84380 R^{3} H^{2}+0.18912 R^{4} H^{2}-0.01721 R^{3} H^{4}-$ $0.02016 \mathrm{R}^{4} \mathrm{H}^{3}-0.00026564 \mathrm{R}^{4} \mathrm{H}^{4}+4.31392 \mathrm{R}^{2} \mathrm{~T}^{2}+0.59154 \mathrm{R}^{3} \mathrm{~T}^{2}+0.03438 \mathrm{R}^{3} \mathrm{~T}^{3}+0.00497 \mathrm{R}^{4} \mathrm{~T}^{3}+$ $0.00003261 \mathrm{R}^{4} \mathrm{~T}^{4}-0.51238 \mathrm{H}^{2} \mathrm{~T}^{2}+0.33980 \mathrm{H}^{3} \mathrm{~T}^{2}-0.49672 \mathrm{H}^{4} \mathrm{~T}^{2}+0.00254 \mathrm{H}^{4} \mathrm{~T}^{4}-6.49058 \mathrm{~S}^{2} \mathrm{H}^{2}-0.98987$ $\mathrm{S}^{3} \mathrm{H}^{2}+4.97361 \mathrm{~S}^{2} \mathrm{H}^{3}+1.21784 \mathrm{~S}^{3} \mathrm{H}^{3}+0.10385 \mathrm{~S}^{4} \mathrm{H}^{3}-0.00003761 \mathrm{~S}^{4} \mathrm{H}^{4}-0.00034935 \mathrm{~S}^{4} \mathrm{R}^{4}-0.61685 \mathrm{~S}^{2} \mathrm{~T}^{2}-$ $0.40559 \mathrm{~S}^{3} \mathrm{~T}^{2}-0.07365 \mathrm{~S}^{4} \mathrm{~T}^{2}+0.13386 \mathrm{~S}^{3} \mathrm{~T}^{3}+0.02383 \mathrm{~S}^{4} \mathrm{~T}^{3}-0.00164 \mathrm{~S}^{4} \mathrm{~T}^{4}-0.00929 \mathrm{~S}^{3} \mathrm{~T}^{4}-0.01461 \mathrm{~S}^{2} \mathrm{~T}^{4}+$ $0.20819 \mathrm{~S}^{2} \mathrm{~T}^{3}+1.05891 \mathrm{R}^{2} \mathrm{H}^{3}$

\subsection{Generic Model for Stainless Steels}

A total of 612 data sets were used from the following stainless steels, SS304, SS304L, SS316, SS316L, SS321, and SS348, to derive a multivariate equation. The dwell times ranged from a few seconds to several hours and temperature varied from room temperature to $700^{\circ} \mathrm{C}$. The total strain range varied from $0.2 \%$ to as high as $2.5 \%$ and strain rate, though not specified for each test, varied from $5 \times 10^{-3}$ to as low as $5 \times 10^{-5} / \mathrm{sec}$. The four independent variables identified were used in the Statistical Analysis System and a best-fit equation was derived for $4^{\text {th }}$ power optimized for maximum $\bar{R}^{2}$ value. It is shown that higher power terms do not contribute to further improvement in the $\mathrm{R}^{2}$ value from the plot, Figure 8 , showing number of terms in a

\section{Term Reduction}

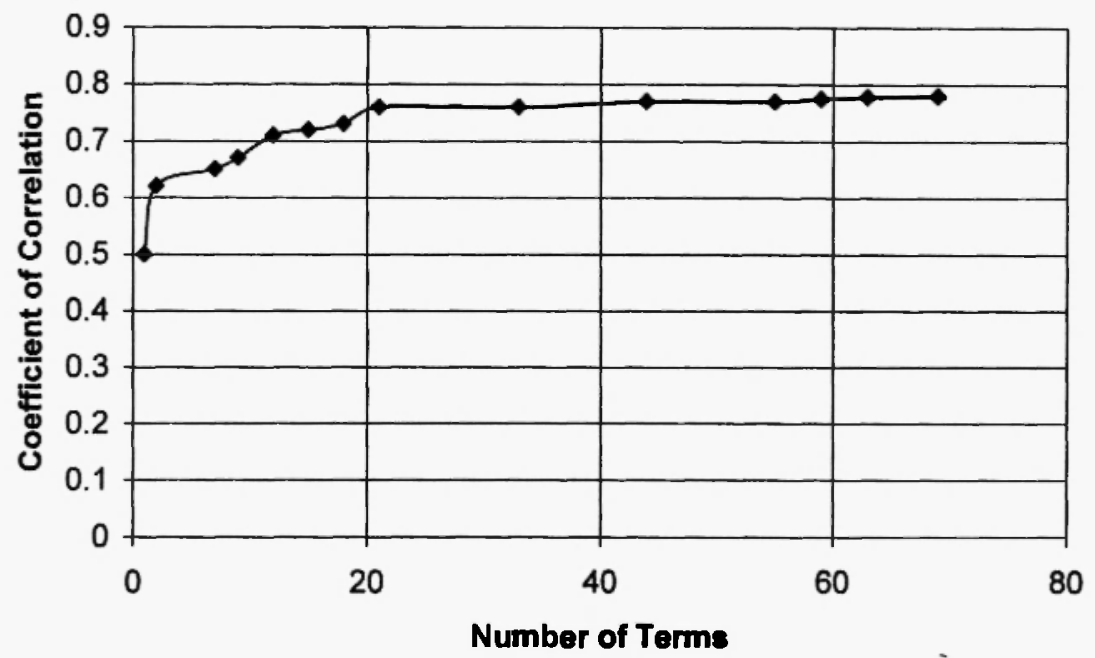

Fig. 8: Number of terms versus coefficient of correlation $\left(R^{2}\right)$ value for stainless steels; this figure shows minimal effects of additional terms in $R^{2}$ improvement after 20 terms. 
plateau, meaning after certain number of terms inclusion of further terms add only marginally to the $\mathrm{R}^{2}$ improvement. The analysis of variance involved a corrected total degree of freedom 611 terms, sum of squares 26.7411 , mean square of $0.30243, \mathrm{~F}$ value of 27.91 . A 69 variable, multivariate equation was developed which gave a $\mathrm{R}^{2}$ value of $78.04 \%$. Thus, $21.96 \%$ of the total variations remain unexplained. This could be due to random test samples that were collected, test run out, premature failures, or to an additional variable, which has not been considered.

Figure 9 shows the residual scatter plot of the experimental and predicted lives under a range of test conditions and data compiled. It is warned that several tests either had run outs or prematurely failed early on in their fatigue life, therefore, those data points are clearly shown in the figure. A statistical analysis in terms of normal cumulative distribution and cumulative distribution of residuals are plotted in Fig. 10. The closer the trend corresponds to 1 to 1 line, the better the model. The observed trend follows very closely the 1 to $I$ line, and therefore has higher reliability ( $78 \%$ success).

The generic model for stainless steel alloys has the following form:

$N_{f}=163.39883+64.20992 S^{2}+7.01704 R^{2}+25.13215 T^{2}+41.65816 \mathrm{~S}^{3}-0.38332 R^{3}-3.26665 \mathrm{~T}^{3}+$ $7.57208 \mathrm{~S}^{4}-0.23007 \mathrm{R}^{4}-36.86686 \mathrm{H}^{4}+0.15386 \mathrm{~T}^{4}+23.85942 \mathrm{SH}+1.85719 \mathrm{~S}^{4} \mathrm{R}-23.61841 \mathrm{RH}-$ $12.08030 \mathrm{RT}+0.02434 \mathrm{HT}-0.13906 \mathrm{R}^{2} \mathrm{~S}-4.66900 \mathrm{R}^{2} \mathrm{~T}+0.99592 \mathrm{R}^{3} \mathrm{H}+0.09961 \mathrm{R} 4 \mathrm{H}+0.49319 \mathrm{R}^{3} \mathrm{~T}+$ $0.16143 \mathrm{R}^{4} \mathrm{~T}+0.02522 \mathrm{R}^{4} \mathrm{~S}+17.33993 \mathrm{H}^{2} \mathrm{~T}-8.96337 \mathrm{H}^{3} \mathrm{~T}-33.69973 \mathrm{H}^{2} \mathrm{R}-20.80409 \mathrm{H}^{4} \mathrm{R}+6.24712 \mathrm{H}^{2} \mathrm{~S}-$ $23.99468 \mathrm{H}^{3} \mathrm{~S}+1.26908 \mathrm{H}^{4} \mathrm{~S}+0.96278 \mathrm{~S}^{2} \mathrm{R}^{2}+0.73930 \mathrm{~S}^{3} \mathrm{R}^{2}+0.13531 \mathrm{~S}^{4} \mathrm{R}^{2}+0.01450 \mathrm{R}^{3} \mathrm{~S}^{3}-0.00620 \mathrm{R}^{4} \mathrm{~S}^{3}$ - 25.82372 $R^{2} H^{2}-5.53079 R^{3} H^{2}-0.37609 R^{4} H^{2}+0.13917 R^{3} H^{3}-0.21810 R^{3} H^{4}+0.01970 R^{4} H^{3}-0.31492$ $R^{2} T^{2}-0.08381 R^{3} T^{2}-0.03459 R^{4} T^{2}+0.00313 R^{4} T^{3}-0.00012748 R^{4} T^{4}-3.15001 H^{2} T^{2}+1.67298 H^{3} T^{2}+$ $0.16910 \mathrm{H}^{4} \mathrm{~T}^{2}+0.18640 \mathrm{H}^{2} \mathrm{~T}^{3}-0.09993 \mathrm{H}^{3} \mathrm{~T}^{3}-0.04251 \mathrm{H}^{4} \mathrm{~T}^{3}+0.00287 \mathrm{H}^{4} \mathrm{~T}^{4}-2.87564 \mathrm{~S}^{2} \mathrm{H}^{2}-2.71987 \mathrm{~S}^{3} \mathrm{H}^{2}$ - $0.44970 \mathrm{~S}^{4} \mathrm{H}^{2}-8.92880 \mathrm{~S}^{2} \mathrm{H}^{3}-0.91209 \mathrm{~S}^{3} \mathrm{H}^{3}+0.04629 \mathrm{~S}^{4} \mathrm{H}^{4}-0.00192 \mathrm{~S}^{4} \mathrm{R}^{4}-10.48912 \mathrm{~S}^{2} \mathrm{~T}^{2}-6.82999$ $\mathrm{S}^{3} \mathrm{~T}^{2}-1.24378 \mathrm{~S}^{4} \mathrm{~T}^{2}+1.34692 \mathrm{~S}^{3} \mathrm{~T}^{3}+0.24474 \mathrm{~S}^{4} \mathrm{~T}^{3}=0.01345 \mathrm{~S}^{4} \mathrm{~T}^{4}=0.07416 \mathrm{~S}^{3} \mathrm{~T}^{4}-0.11433 \mathrm{~S}^{2} \mathrm{~T}^{4}+2.07277$ $\mathrm{S}^{2} \mathrm{~T}^{3}-3.72231 \mathrm{R}^{2} \mathrm{H}^{4}$

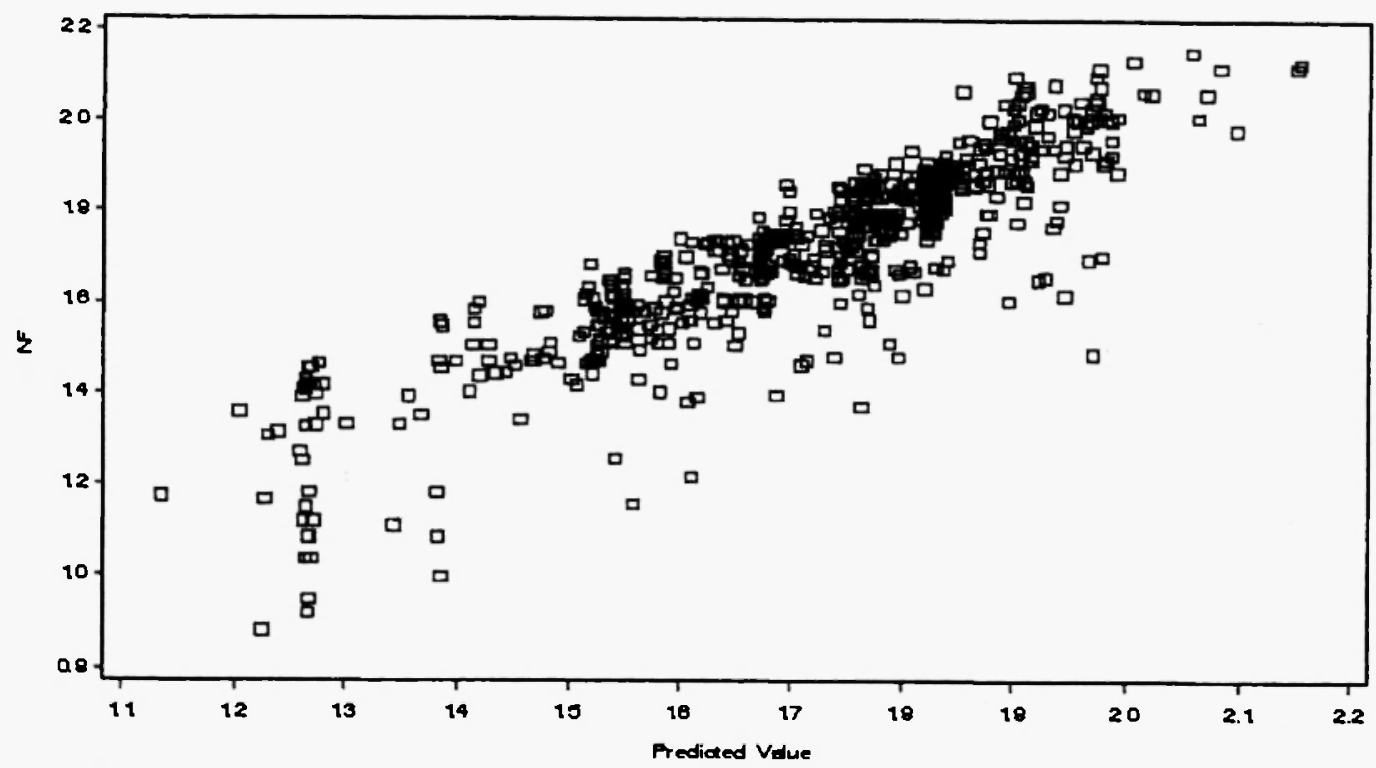

Fig. 9: Scatter plot of experimental and predicted lives of stainless steels (612 data sets). 


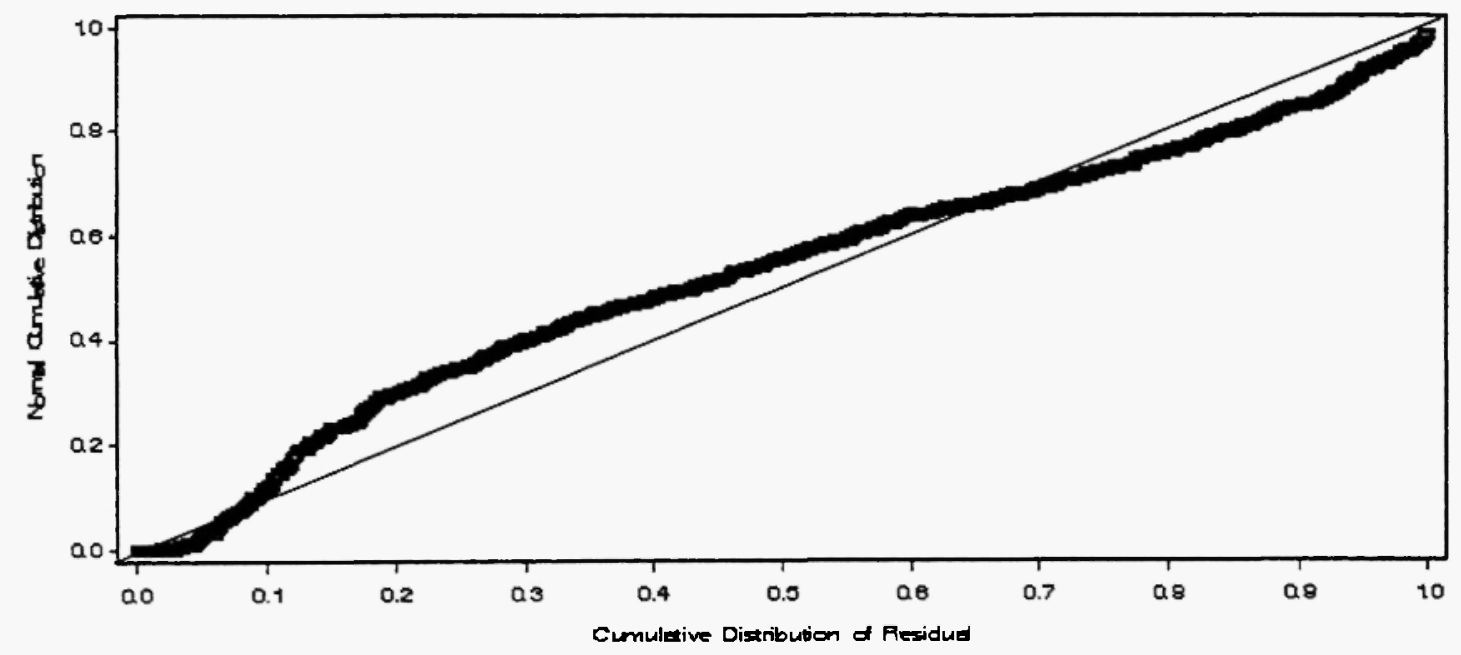

Fig. 10: Normal cumulative distribution versus cumulative distribution of residuals showing a straight line behavior (Scale is 1 to 1,612 data sets).

\subsection{Generic Model for High Temperature Materials}

A total of 1782 data sets were used from the following high temperature alloys, a major part of that data was presented in (15-16) while studying dwell sensitivity behavior:

a) Solder alloys

b) Copper alloys

c) Steel alloys

1) Cr-Mo low alloy steels

2) Stainless steels

d) Titanium alloys

e) Tantalum alloys

f) Ni-based alloys

The dwell times ranged from a few seconds to several hours and temperature varied from room temperature to $1100^{\circ} \mathrm{C}$. The total strain range varied from $0.1 \%$ to as high as $5 \%$ and strain rate, though not specified for each test, varied from $5 \times 10^{-3}$ to as low as $5 \times 10^{-5} / \mathrm{sec}$. The four independent variables identified were used in the Statistical Analysis System and a best-fit equation was derived for $4^{\text {th }}$ power optimized for maximum $\mathrm{R}^{2}$ value. It is shown that higher power terms do not contribute to further improvement in the $\mathrm{R}^{2}$ value from the plot. Figure 11 , showing number of terms in a plateau, meaning that after a certain number of terms inclusion of further terms adds only marginally to the $R^{2}$ improvement. The analysis of variance involved a corrected total degree of freedom 1776 terms, sum of squares 105.53 , mean square of $0.82897, \mathrm{~F}$ value of 34.44 . A 78 variable, multivariate equation was developed which produced a $R^{2}$ value of $61.27 \%$. Thus, $38.73 \%$ of the total variations remain unexplained. This could be due to random test samples that were collected on so many different materials ranging from solder alloys to superalloys, test run out, premature failures, or to an additional variable, which has not been considered. 




Fig. 11: Number of terms versus coefficient of correlation $\left(R^{2}\right)$ value for generic materials (1782 data sets).

Figure 12 shows the residual scatter plot of the experimental and predicted lives under a range of test conditions and data compiled. It is warned that several tests either had run outs or prematurely failed early on in their fatigue life, therefore, those data points are clearly showing in the figure. Also, this particular combination of materials was very complex, in that the melting temperature varied from above room temperature for solder alloys to around $1600^{\circ} \mathrm{C}$ for Ni-based alloys. While solder alloys operate at room temperatures, these alloys are used at higher homologous temperatures than all other materials studied here. A statistical analysis in terms of normal cumulative distribution and cumulative distribution of residuals are plotted in Fig. 13. The closer the trend corresponds to I to I line, the better the model. The observed trend follows very closely the I to I line, and therefore has higher reliability (61\% success).

The 78 term, generic model, for high temperature materials has the following form:

$\mathrm{N}_{\mathrm{f}}=0.08317+1.09592 \mathrm{~S}^{2}+0.28803 \mathrm{R}^{2}-3.92644 \mathrm{H}^{2}+0.11683 \mathrm{~T}^{2}+0.12602 \mathrm{~S}^{3}+0.08337 \mathrm{R}^{3}+0.48073 \mathrm{H}^{3}-$ $0.02490 T^{3}-0.01410 S^{4}+0.00427 R^{4}-0.07199 H^{4}+0.00136 T^{4}+0.05327 S R-0.00292 S^{3} T+0.99189 R H+$ $0.00582 R T+0.09628 H T+0.07534 R^{2} S+0.02614 R^{2} H-0.07225 R^{3} H-0.00807 R^{4} H+0.01471 R^{3} T+$ $0.00271 R^{4} T+0.04763 R^{3} S+0.00489 R^{4} S-0.23417 H^{2} T+0.15182 H^{3} T+0.03809 H^{4} T-0.78985 H^{2} R+$ $0.20922 \mathrm{H}^{3} \mathrm{R}-0.01827 \mathrm{H}^{4} \mathrm{R}-6.30474 \mathrm{H}^{2} \mathrm{~S}+1.05744 \mathrm{H}^{3} \mathrm{~S}+0.01944 \mathrm{H}^{4} \mathrm{~S}-0.07108 \mathrm{~S}^{2} \mathrm{R}^{2}-0.00131 \mathrm{~S}^{4} \mathrm{R}^{2}$ $0.01761 R^{2} S^{3}-0.00089565 R^{3} S^{3}-0.00019713 R^{4} S^{3}+0.15444 R^{2} H^{2}+0.10979 R^{3} H^{2}+0.01101 R^{4} H^{2}-$ $0.04600 \mathrm{R}^{3} \mathrm{H}^{3}+0.00573 \mathrm{R}^{3} \mathrm{H}^{4}-0.00438 \mathrm{R}^{4} \mathrm{H}^{3}+0.00052764 \mathrm{R}^{4} \mathrm{H}^{4}-0.00126 \mathrm{R}^{2} \mathrm{~T}^{2}-0.00209 \mathrm{R}^{1} \mathrm{~T}^{2}-$ $0.00041344 \mathrm{R}^{4} \mathrm{~T}^{2}+0.00006870 \mathrm{R}^{3} \mathrm{~T}^{3}+0.00002351 \mathrm{R}^{4} \mathrm{~T}^{3}-4.70403 \mathrm{E}-7 \mathrm{R}^{4} \mathrm{~T}^{4}+0.01583 \mathrm{H}^{2} \mathrm{~T}^{2}-0.01689 \mathrm{H}^{3} \mathrm{~T}^{2}$ $-0.00899 \mathrm{H}^{4} \mathrm{~T}^{2}-0.00059596 \mathrm{H}^{2} \mathrm{~T}^{3}+0.00076001 \mathrm{H}^{3} \mathrm{~T}^{3}+0.00087790 \mathrm{H}^{4} \mathrm{~T}^{3}-0.00003188 \mathrm{H}^{4} \mathrm{~T}^{4}-3.79717$ $\mathrm{S}^{2} \mathrm{H}^{2}-0.95991 \mathrm{~S}^{3} \mathrm{H}^{2}=0.08619 \mathrm{~S}^{4} \mathrm{H}^{2}+0.68806 \mathrm{~S}^{2} \mathrm{H}^{3}+0.17249 \mathrm{~S}^{3} \mathrm{H}^{3}+0.01406 \mathrm{~S}^{4} \mathrm{H}^{3}+0.00026628 \mathrm{~S}^{4} \mathrm{H}^{4}=$ $0.00001764 \mathrm{~S}^{4} R^{4}+0.06530 \mathrm{~S}^{2} \mathrm{~T}^{2}+0.05116 \mathrm{~S}^{3} \mathrm{~T}^{2}+0.00915 \mathrm{~S}^{4} \mathrm{~T}^{2}-0.00887 \mathrm{~S}^{3} T^{3}-0.00163 \mathrm{~S}^{4} \mathrm{~T}^{3}+$ $0.00007714 \mathrm{~S}^{4} T^{4}+0.00040737 \mathrm{~S}^{3} \mathrm{~T}^{4}+0.00043237 \mathrm{~S}^{2} \mathrm{~T}^{4}-0.01039 \mathrm{~S}^{2} \mathrm{~T}^{3}-0.09279 \mathrm{R}^{2} \mathrm{H}^{3}+0.01364 \mathrm{R}^{2} \mathrm{H}^{4}$ 


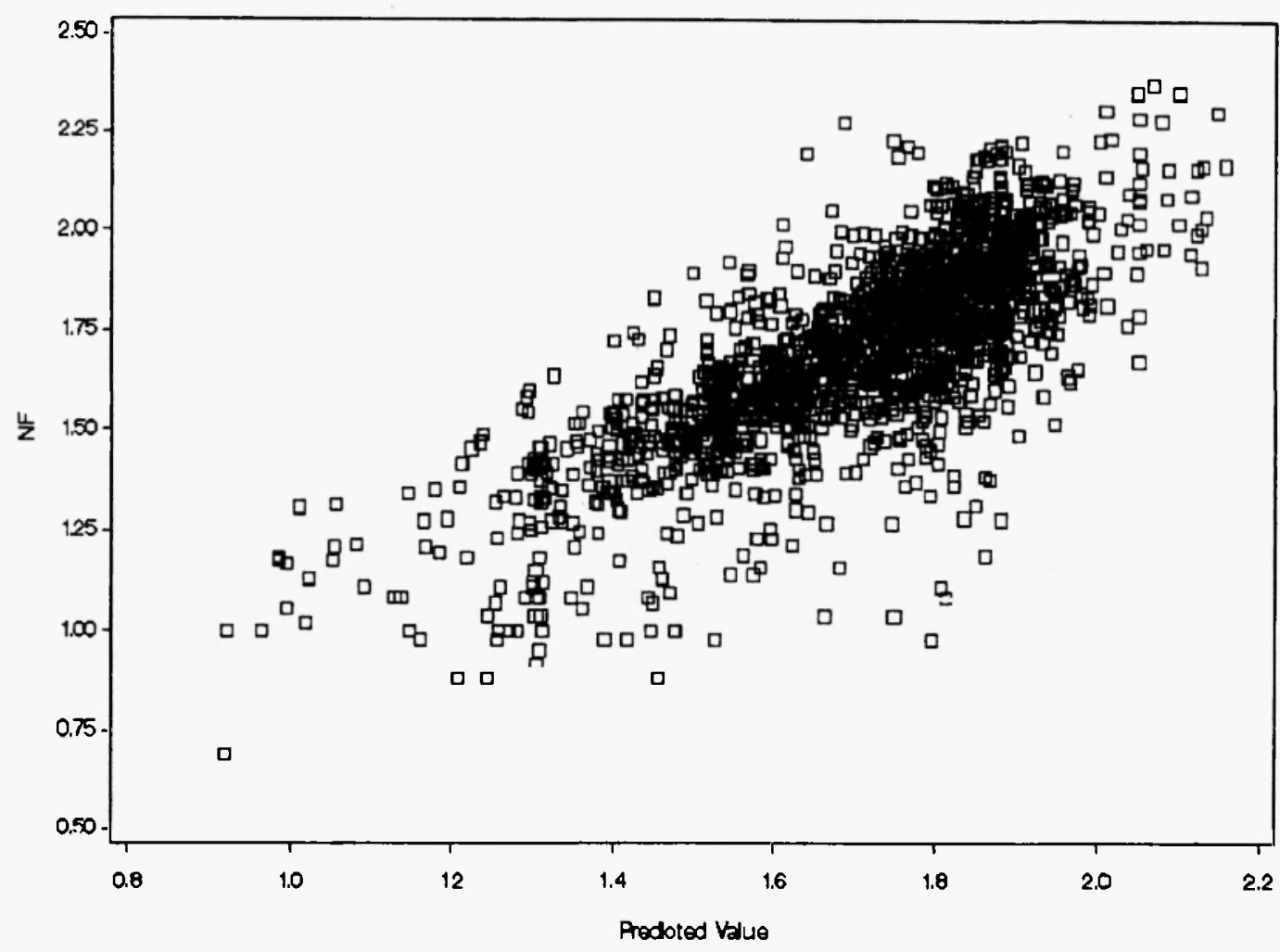

Fig. 12: Scatter plot of experimental and predicted lives of generic materials (1782 data sets).

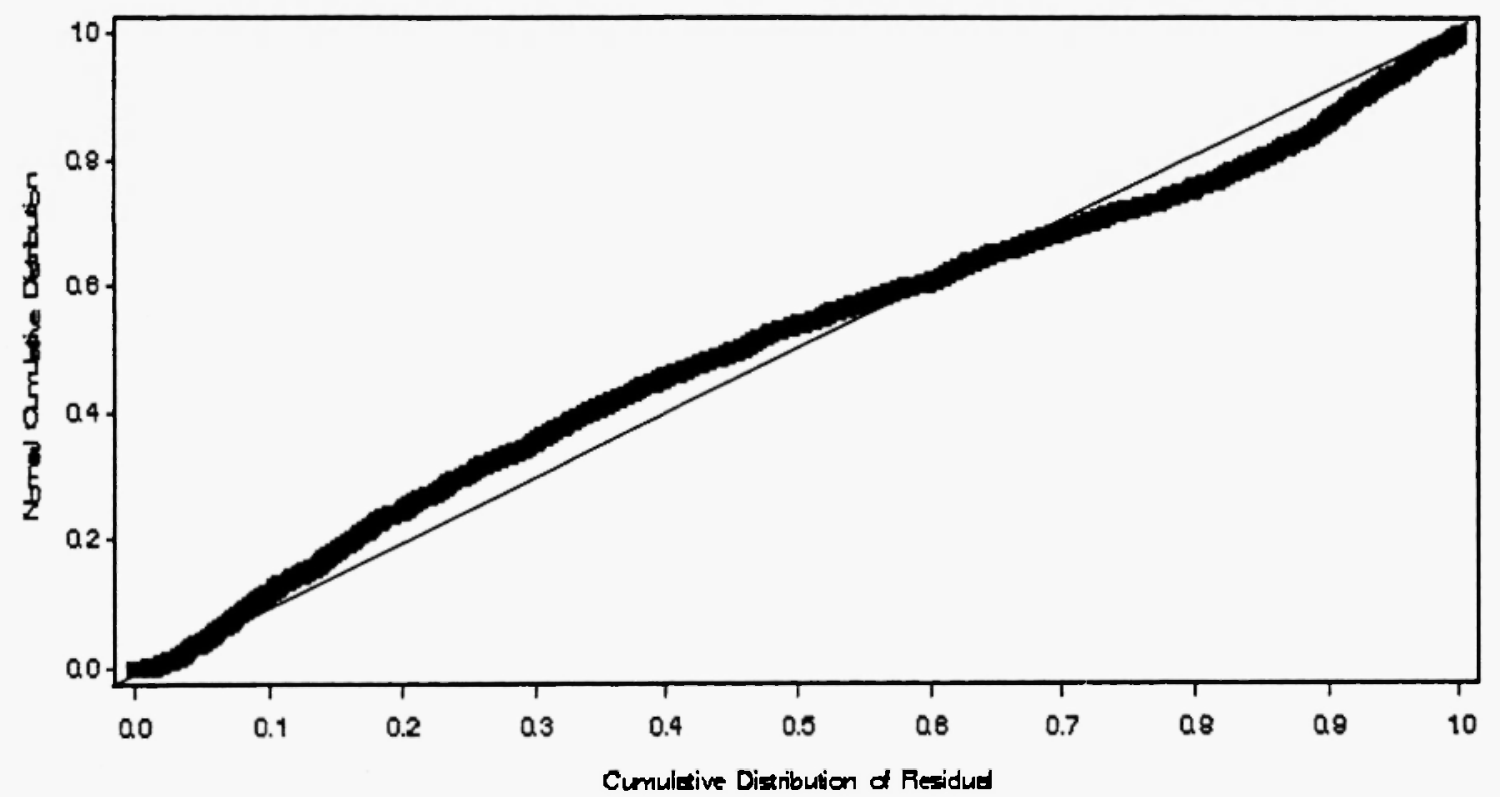

Fig. 13: Normal cumulative distribution versus cumulative distribution of residuals showing a straight line behavior (Scale is I to 1.782 data sets). 
where $\mathrm{S}, \mathrm{R}, \mathrm{T}$ and $\mathrm{H}$ are independent variables and have assigned transformed values identified earlier.

The methodology used to derive the above equations has been established using several software packages. Future work will include further refining the parameters that were applied to the databank that was compiled over the years. Subsequently, a window based computer program will be developed to perform the life prediction analysis for new data that was not included in the main database and results will be published as an addendum, or as a new applicability paper. Therefore, applicability of these equations is not discussed in this paper using generic methods.

\section{CONCLUSIONS}

1) A methodology was established to generate multivariate life prediction equations for low alloy steels, stainless steels, and generic high temperature materials.

2) New models developed in this paper were found to be statistically conservative, showing a very close normal distribution plots and a very high coefficient of correlation value. In the worst-case scenario, only $39 \%$ of total variations remain unexplained and database included a range of materials from solder alloys to superalloys. Therefore, these methods have a potential of use in the design, the planning of experimental programs, and use where test data are not available.

3) Applicability of the multivariate equations presented in this paper has not been assessed with new data. Therefore, future work will involve writing a software, new data collection, and assessment will be performed in the near future and published in this Journal as a follow-up paper.

\section{REFERENCES}

1. Goswami, T. (1997) International Journal of Fatigue, 19, 2, p 109

2. Goswami, T. (1995) High Temperature Materials and Processes, 14, 2, p. 101.

3. Toland, J. and Goswami, T. (2002) Mechanical Behavior of Materials, 13, 5-6, pp. 387-396.

4. Anon, Code Case N-47, (1976) ASME Boiler and Pressure Vessel Code, Criteria for Design of Elevated Temperature, Class 1 Components in Section III, Division I, American Society of Mechanical Engineers.

5. Manson, S. S., Halford, G. R. and Hirschberg, M. H. (1971) NASA Report TMX 67838.

6. Coffin, L. F. (1974) Fatigue at High Temperature and Interpretation, Proceedings of Institute of Mechanical Engineers, 9/74, p. 188.

7. Majumdar. S. and Maiya, P. S. (1978) ASME/CSME Pressure Vessel and Piping Conference, PVP-PB 028.

8. Ostergren, W. J. (1976) Journal of Testing and Evaluation 4, p. 327.

9. Chrzanowski, N. (1976) International Journal of Mechanical Science, 18, pp. 69-73.

10. Goodall, I. W. and Thomas, D. L. (1990) Nuclear Electric Inc. Code R-5.

11. Diercks. D. R. and Raskey, D. T. (1976), ASME Annual Winter Meeting, pp. 1-33.

12. Sonoya, K., Nonaka, I. and Kitagawa, M. (1991) Iron and Steel Institute of Japan. International Journal, 31, pp. 1424-1430. 
13. Langer, B. F. (1962) American Society of Mechanical Engineers, Journal of Basic Engineering. 84, 3, pp. 389-402.

14. Goswami, T. (2003) Creep-fatigue life prediction of Cr-Mo steel alloys, Materials Lifetime Science and Engineering, Edited by Laiw PK, Buchanan, RA, Klarstrom, DL, Wei, RP, Harlow, DG and Tortorelli, PF, TMS, pp. 43-50.

15. Goswami, T. and Hanninen, H. (2001) Materials and Design, 22, 3, pp. 199-215.

16. Goswami, T. and Hanninen, H. (2001) Materials and Design, 22, 3, pp. 217-236. 